\title{
Perbandingan Metode Multichannel Analysis of Surface Wave dan Metode Cone Penetration Test Terhadap Analisis Lapisan Tanah
}

\author{
Cut Atika Hasya ${ }^{1}$ Khaizal $^{2}$ Irwandi $^{3}$ \\ 1,2,3 Jurusan Teknik Sipil, Universitas Syiah Kuala, Banda Aceh 23111, Indonesia \\ Email: atikasyaa@yahoo.co.id
}

\begin{abstract}
One of the soil layers analysis conducted in the field is the Cone Penetration Test (CPT) method which produces the main parameters of cone tip endurance (qc). Whereas, the Surface Wave Multichannel Analysis (MASW) method is a method from the field of geophysics to analyze soil layers that can produce shear wave velocity parameters (Vs). This study aims to obtain shear wave parameters (Vs) MASW and CPT tip endurance parameters to analyze the soil layer and compare the results of the two methods to the characteristics of the soil layer as a civil building foundation planning. Data acquisition was conducted at TPI (Fish Landing Place) Lampulo, Kuta Alam District. The results of the study on MASW measurements obtained a value of Vs of 70-130 m/s. Based on SNI 1726-2012, the soil at the research location is included in the category of Soft Soil (SE). CPT data that has been correlated using empirical equations into Vs values show relatively similar results to the soil classification in MASW. The appropriate type of foundation applied at the study sites is the pile foundation because it places the ground harder than at a height of more than 10 meters below the surface of the ground.
\end{abstract}

Keywords: Soil layer, MASW, CPT.

Analisis lapisan tanah yang dilakukan di lapangan salah satunya, metode Cone Penetration Test (CPT) yang menghasilkan parameter utama nilai tahanan ujung konus (qc). Sedangkan, metode Multichannel Analysis of Surface Wave (MASW) adalah metode dari bidang ilmu geofisika untuk menganalisis lapisan tanah yang dapat menghasilkan parameter kecepatan gelombang geser (Vs). Penelitian ini bertujuan untuk mendapatkan parameter gelombang geser (Vs) MASW dan parameter tahanan ujung CPT untuk menganalisis lapisan tanah serta membandingkan hasil dari kedua metode tersebut terhadap karakteristik lapisan tanah sebagai perencanaan pondasi bangunan sipil. Akuisisi data dilakukan di TPI (Tempat Pendaratan Ikan) Lampulo, Kecamatan Kuta Alam. Hasil penelitian pada pengukuran MASW didapatkan nilai Vs sebesar $70-130 \mathrm{~m} / \mathrm{s}$. Berdasarkan SNI 1726-2012, tanah pada lokasi penelitian termasuk ke dalam kategori Tanah Lunak (SE). Data CPT yang telah dikorelasikan meggunakan persamaan empiris menjadi nilai Vs menunjukkan hasil yang relatif sama dengan klasifikasi tanah pada MASW. Jenis pondasi yang sesuai diterapkan pada lokasi penelitian adalah pondasi tiang karena letak tanah keras berada pada kedalaman lebih dari 10 meter dibawah permukaan tanah.

Kata Kunci: Lapisan tanah, MASW, CPT.

\section{Pendahuluan}

Analisis lapisan tanah meliputi banyak pengujian, baik pengujian langsung di lapangan maupun di laboratorium. Pengujian biasanya dilakukan dengan metode CPT (Cone Penetration Test), SPT (Standard Penetration Test), DCP (Dynamic Cone Penetrometer), Vane Shear Test, dan lain-lain. Pengujian-pengujian ini telah diterima oleh praktisi dan pakar geoteknik karena hasilnya selalu teruji. Dalam hal penerapannya, pengujianpengujian ini menghabiskan biaya yang besar karena dilakukan pengeboran. Dengan adanya perkembangan dibidang teknologi, bidang ilmu geofisika telah menemukan alat serta metode untuk penyelidikan lapisan bawah permukaan tanah, salah satunya gelombang seismik.

Gelombang seismik akan menghasilkan beberapa parameter, diantaranya kecepatan gelombang geser (Vs). Kecepatan gelombang geser adalah parameter yang

Journal of The Civil Engineering Student

Vol. 3. No. 1, April 2021, Halaman 8-14 digunakan untuk menentukan karakteristik tanah melalui daya dukung dinamik dan perilaku tanah dalam kondisi elastik. Kecepatan gelombang geser ini diperoleh dari metode MASW (Multichannel Analysis of Surface Wave). Metode penelitian yang dipakai pada penelitian ini adalah metode MASW dan metode CPT. Metode MASW merupakan metode yang dapat merekam perambatan gelombang Rayleigh dalam menginvestigasi karakteristik mekanis lapisan bawah permukaan serta tingkat kepadatan batuan. Metode MASW mulai menjadi alternatif dalam menganalisis lapisan tanah dikarenakan biayanya relatif murah, akuisisi dan pengolahan data mudah, ukuran serta berat peralatan tidak terlalu besar maka bisa dibawa dengan tenaga manusia, lebih ramah lingkungan. Namun, dalam penerapannya, metode MASW masih jarang digunakan oleh para praktisi dan pakar geoteknik untuk menganalisis lapisan tanah karena para pekerja konstruksi masih lebih yakin oleh hasil yang didapatkan dari metode 
lainnya seperti metode CPT. Lokasi penelitian dilakukan di TPI (Tempat Pendaratan Ikan) Lampulo, Kecamatan Kuta Alam.

Penelitian ini memiliki tujuan untuk mendapatkan parameter gelombang geser (Vs) menggunakan metode MASW dan parameter tahanan konus CPT untuk menganalisis lapisan tanah serta membandingkan hasil yang didapatkan dari kedua metode tersebut terhadap karakteristik lapisan tanah sebagai perencanaan pondasi bangunan sipil. Batasan masalah dalam penelitian ini adalah metode MASW dilakukan dengan pengukuran sepanjang 4 lintasan dengan spasi geophone 1,5 $\mathrm{m}$ dan metode CPT dilakukan tiga titik pengujian.

\section{Tinjauan Kepustakaan}

\subsection{Analisis Lapisan Tanah di Lapangan}

Menurut Hardiyatmo[1], Analisis lapisan tanah di lapangan dibutuhkan sebagai data perencanaan pondasi bangunan. Analisis lapisan tanah dapat dilakukan tergantung pada maksud dan tujuannya, misalnya dengan cara test pit, pengeboran, dan in-situ test. Dari data yang diperoleh, sifat-sifat teknis tanah dipelajari, kemudian digunakan sebagai bahan pertimbangan dalam menganalisis perencanaan pondasi.

\subsection{Metode Multichannel Analysis of Surface Wave (MASW)}

Menurut Park, et al[2], metode MASW merupakan metode seismik yang memanfaatkan sifat dispersi dari gelombang permukaan. Gelombang yang digunakan pada metode MASW adalah gelombang Rayleigh untuk analisis geoteknik berdasarkan nilai kecepatan geser (Vs) dari perlapisan tanah yang akan diuji.

Metode MASW memiliki beberapa keunggulan yaitu dalam segi biaya lebih murah karena tidak diperlukan pengeboran, alat yang digunakan mudah dibawa dengan tenaga manusia, dapat digunakan survei dangkal maupun mencapai ratusan meter serta memiliki keunggulan dalam menghasilkan sinyal yang tinggi untuk rasio noise $(\mathrm{S} / \mathrm{N})$. Maka, dalam proses akuisisi data metode ini lebih efektif mengontrol noise sesuai dengan yang telah dilakukan oleh Yeni[3].

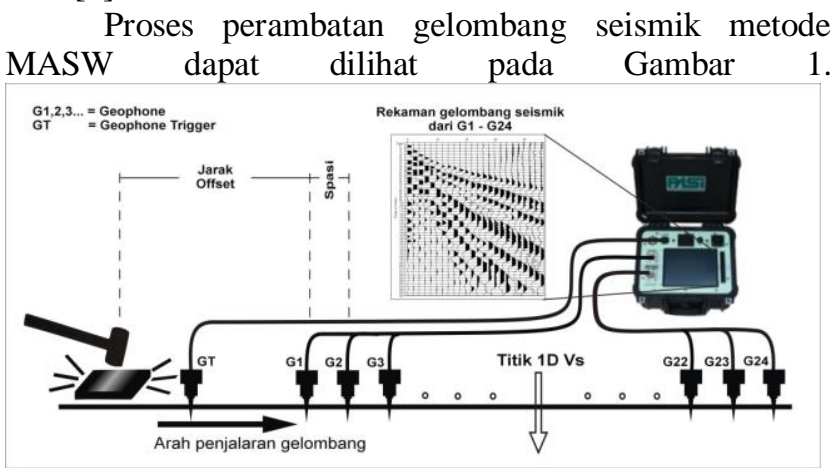

\section{Gambar 1 Proses Perambatan Gelombang Seismik Metode MASW}

Nilai Vs yang didapatkan dari hasil pengukuran MASW di lapangan dilakukan klasifikasi tanah berdasarkan SNI 1726-2012[4]. Rentang nilai Vs untuk klasifikasi jenis tanah menurut SNI 1726-2012 dapat dilihat pada Tabel 1 .

Tabel 1 Klasifikasi Jenis Tanah dan Batuan Menurut SNI 1726-2012

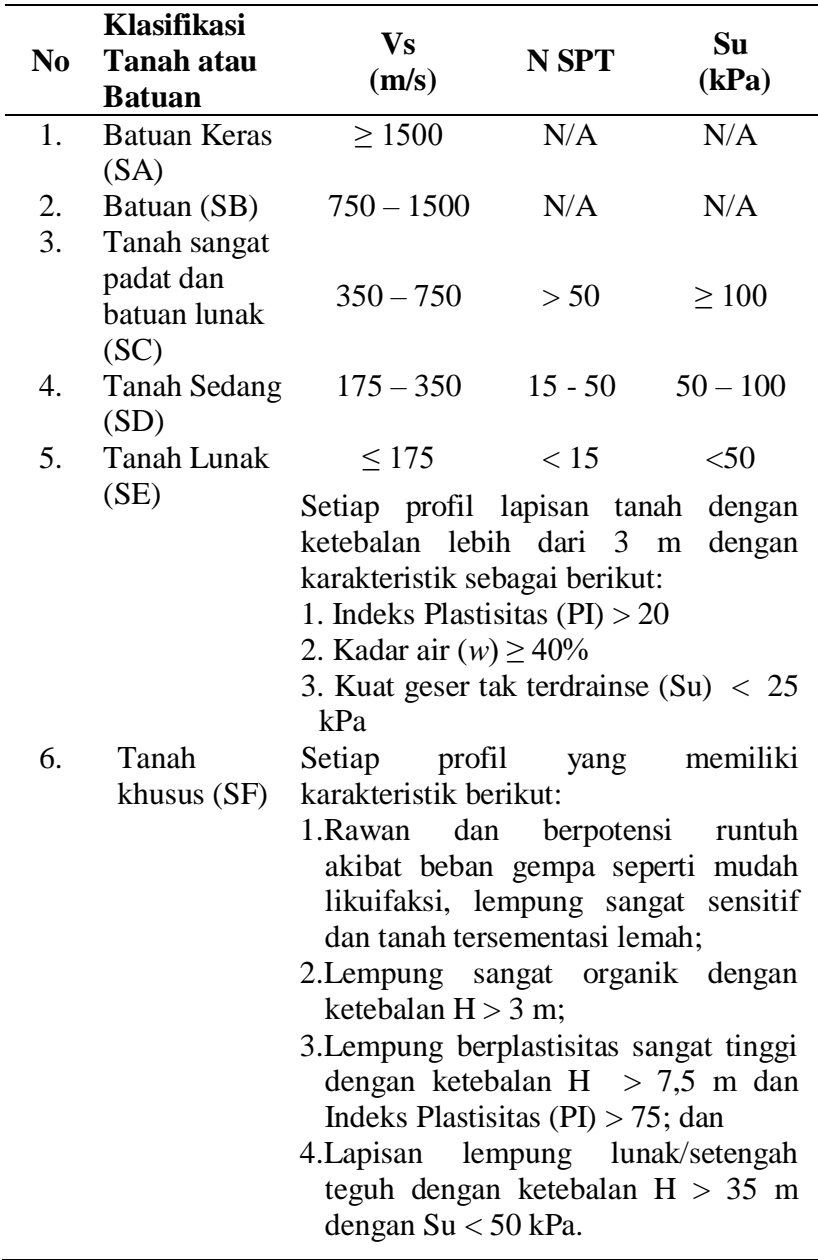

\subsection{Metode Cone Penetration Test (CPT)}

Metode CPT atau di Indonesia disebut uji sondir merupakan pengujian yang sering digunakan dan telah diterima oleh pakar serta praktisi teknik sipil di Indonesia. Metode ini pertama kalinya dikembangkan oleh para insinyur Belanda di laboratorium Delfi, Belanda sehingga disebut juga "Dutch Cone Test" dan digunakan untuk pertama kalinya pada tahun 1935. Klasifikasi tanah menggunakan metode CPT berdasarkan grafik dari Robertson dan Campanella dalam Hardiyatmo[5] dapat dilihat pada Gambar 2. Adapun, konsistensi tanah lempung berdasarkan metode CPT dapat dilihat pada Tabel 2. 
Sedangkan, konsistensi tanah pasir berdasarkan metode CPT dapat dilihat pada Tabel 3.

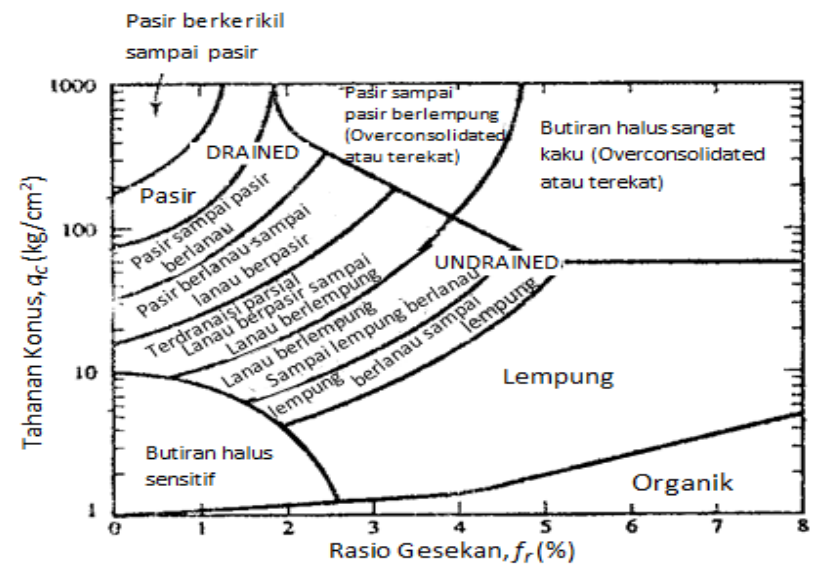

Gambar 2 Klasifikasi Tanah Berdasarkan Metode CPT

Tabel 2 Konsistensi Tanah Lempung Berdasarkan Metode CPT

\begin{tabular}{lcc}
\hline \multicolumn{1}{c}{ Konsistensi } & $\begin{array}{c}\text { Tahanan Konus, } \\
\text { qc }\left(\mathrm{kg} / \mathrm{cm}^{2}\right)\end{array}$ & $\begin{array}{r}\text { Rasio } \\
\text { Gese } \\
\text { kan, } \\
\text { Fr }(\%)\end{array}$ \\
\hline Sangat Lunak/Very Soft & $<5$ & 3,5 \\
Lunak/Soft & $5-10$ & 3,5 \\
Teguh/Firm & $10-35$ & 4,0 \\
Kaku/Stiff & $30-60$ & 4,0 \\
Sangat Kaku/Very stiff & $60-120$ & 6,0 \\
Keras/Hard & $>120$ & 6,0 \\
\hline
\end{tabular}

Tabel 3 Konsistensi Tanah Pasir Berdasarkan Metode CPT

\begin{tabular}{lcc}
\hline \multicolumn{1}{c}{ Konsistensi } & $\begin{array}{c}\text { Tahanan Konus, } \\
\mathrm{qc}\left(\mathrm{kg} / \mathrm{cm}^{2}\right)\end{array}$ & $\begin{array}{c}\text { Rasio Gesekan, } \\
\mathrm{Fr}(\%)\end{array}$ \\
\hline Sangat Lepas/Very Loose & $<20$ & 2,0 \\
Lepas/Loose & $20-40$ & 2,0 \\
Setengah Lepas/Medium & $40-120$ & 2,0 \\
Padat/Dense & $120-200$ & 4,0 \\
Sangat Padat/Very Dense & $>200$ & 4,0 \\
\hline
\end{tabular}

\subsection{Korelasi Nilai Vs dan Nilai Qc}

Korelasi antara nilai Vs (kecepatan geser) dan qc (tahanan ujung) tidak terdapat korelasi langsung. Tetapi, terdapat korelasi langsung antara nilai Vs dan nilai N-SPT. Maka, nilai qc dikorelasikan dengan nilai N-SPT terlebih dahulu meggunakan persamaan dari Terzaghi, et al[6].

$q c=2,5 \times N$ (untuk tanah lempung)

$q c=4 \times N$ (untuk tanah pasir).

Keterangan:

$q c \quad=$ nilai tahanan ujung konus $\left(\mathrm{kg} / \mathrm{cm}^{2}\right)$

$\mathrm{N}=$ nilai $\mathrm{N}-\mathrm{SPT}$

Menurut Marto, et al[7], Korelasi antara N-SPT dan Vs dalam bentuk persamaan empiris telah banyak ditemukan, dengan format $\mathrm{Vs}=\mathrm{AN}^{\mathrm{B}}$. Masing-masing korelasi empiris tersebut didapatkan dari hasil penelitian di berbagai belahan dunia dengan kondisi geologi, sifat dan jenis tanah yang berbeda-beda. Pada penelitian ini persamaan empiris dari Kanai dalam Marto, et al yang digunakan, persamaannya adalah sebagai berikut,

$$
V s=19 \times N^{0,6}
$$

Keterangan:

$$
\text { Vs = Kecepatan Gelombang Geser }(\mathrm{m} / \mathrm{s})
$$$$
\mathrm{N} \quad=\text { Nilai } \mathrm{N}-\mathrm{SPT}
$$

Persamaan ini yang digunakan didasari karena M. Rizki[8] telah memakai persamaan yang sama di lokasi Banda Aceh dan memiliki tingkat kesesuaian nilai Vs korelasi yang paling mendekati dengan nilai Vs pengukuran MASW yang tinggi dibandingkan dengan persamaan empiris lainnya.

\subsection{Pemilihan Tipe Pondasi Berdasarkan Metode CPT}

Pemilihan tipe pondasi berdasarkan metode CPT berhubungan dengan terletaknya tanah keras pada kedalaman tertentu. Ada beberapa tipe pondasi menurut letak tanah kerasnya berdasarkan teori dari Sosrodarsono, dan Nakazawa[9]:

1. Jika tanah keras terdapat pada permukaan tanah atau berada 2-3 meter di bawah permukaan tanah, maka dipergunakan pondasi telapak (spread foundation).

2. Jika tanah keras terdapat pada kedalaman sekitar 10 meter di bawah permukaan tanah, maka dipergunakan pondasi tiang atau pondasi tiang apung (floating pile foundation) untuk memperbaiki tanah pondasi.

3. Jika tanah keras terdapat pada kedalaman sekitar 20 meter di bawah permukaan tanah, serta boleh terjadi penurunan yang diizinkan digunakan pondasi tiang pancang (pile driven foundation). Tetapi, jika digunakan batu besar (cobble stones) pada lapisan antara pemakaian kaison lebih menguntungkan.

4. Jika tanah keras terdapat pada kedalaman sekitar 30 meter di bawah permukaan tanah, maka digunakan pondasi kaison terbuka, tiang baja atau tiang yang dicor di tempat.

5. Jika tanah keras terdapat pada kedalaman lebih dari 40 meter di bawah permukaan tanah, makadigunakan pondasi tiang baja dan tiang beton yang dicor di tempat.

\section{Metodologi Penelitian}

Langkah dalam penelitian ini dimulai dengan akuisisi data seismik MASW di lapangan, pengolahan data MASW, interpretasi data seismik MASW dan data CPT, dilakukan perbandingan antara keduanya berdasarkan klasifikasi tanah menggunakan SNI 1726-2012. 


\subsection{Lokasi Pengukuran Data}

Lokasi pengukuran data terdapat pada TPI Lampulo, Kecamatan Kuta Alam, Banda Aceh. Proses pengujian metode MASW dilakukan pengukuran 4 lintasan secara overlap spasi geophone $1,5 \mathrm{~m}$. Proses pengujian CPT dilakukan tiga titik pengujian. Lokasi titik pengujian ditampilkan pada Gambar 3.

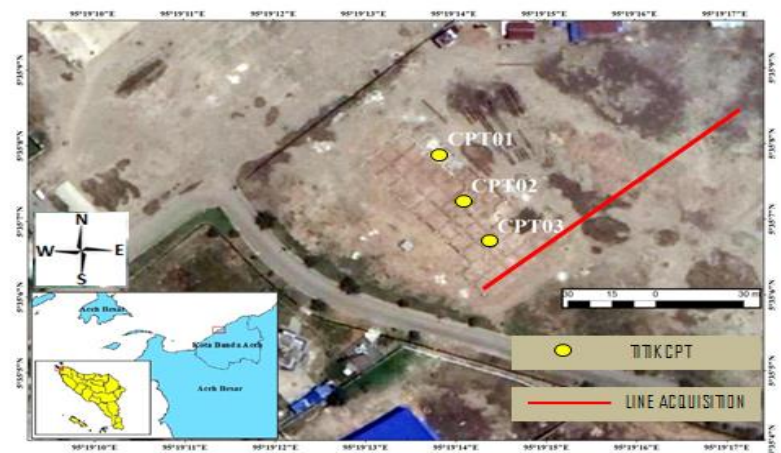

Gambar 3 Lokasi Penelitian Pada TPI Lampulo

\subsection{Sumber Data}

Data yang dipakai untuk penelitian ini terdiri dari data primer dan data sekunder. Data primer adalah data yang didapatkan dengan melakukan akuisisi data seismik MASW di lapangan. Sedangkan, data sekunder adalah data yang didapatkan dari luar penelitian atau dari instansi yang terkai, yaitu peta lokasi penelitian dan data CPT.

\subsection{Teknik Pengumpulan Data}

Pengumpulan data seismik MASW dilakukan menggunakan alat dan bahan seperti yang terlihat pada Gambar 4.

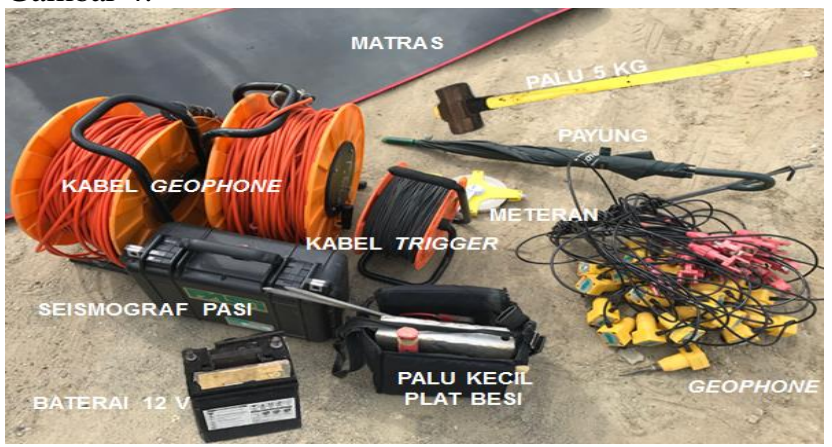

Gambar 4 Alat dan Bahan Metode MASW

Pengumpulan data seismik MASW diawali dengan pemasangan alat pada lokasi penelitian. Geophone yang berjumlah 24 buah pada setiap lintasan dipasang dengan jarak antar geophone 1,5 m menggunakan jarak far offset pertama dan terakhir adalah $15 \mathrm{~m}$. Kabel geophone dibentangkan dan dihubungkan antara konektor geophone dengan konektor kabel. Kemudian, Seismograf PASI dihubungkan dengan baterai 12 Volt dan diposisikan di antara geophone ke-12 dan ke-13.
Setelah pemasangan alat selesai dan Seismograf PASI telah hidup maka, dilanjutkan dengan membuat nama file baru pada Seismograf PASI dengan memilih pilihan acquisition dan memilih tombol add note sesuai dengan nama lokasi penelitian serta mengatur record time. Selanjutnya, trigger ditancapkan tepat di sebelah plat besi dan diberikan sumber seismik berupa pukulan dari palu seberat $5 \mathrm{~kg}$ keatas plat besi. Lalu, hasil dari perekaman gelombang dapat dilihat dengan cara memilih pilihan load pada Seismograf PASI. Langkah terakhir yaitu menggandakan (copy) data yang telah terekam oleh Seismograf ke dalam USB Drive untuk dilakukan analisis data dengan format data yaitu DAT.

\subsection{Teknik Analisis Data}

Analisis data seismik MASW dilakukan di Geotechnical Imaging and Sensing Centre, Jurusan Teknik Sipil, Fakultas Teknik, Universitas Syiah Kuala. Analisis data seismik MASW menggunakan software SeisImager dengan mengikuti panduan manual SeisImager/SM ${ }^{T M}$. Pengolahan data menggunakan software tersebut, terdapat dua tahap yang harus dilakukan yaitu proses dispersi dan inversi. Tahap dispersi dilakukan untuk mendapatkan nilai kecepatan fase (phase velocity) dan frekuensi dalam bentuk kurva dispersi. Perhitungan kecepatan gelombang geser sebagai fungsi kedalaman dilakukan dengan cara menginversikan kurva dispersi seluruh shoot yang ditangkap oleh setiap geophone karena setiap geophone menghasilkan satu profil kecepatan gelombang geser terhadap kedalaman. Sedangkan, tahap inversi dilakukan pencocokan antara kurva dispersi teori dan kurva dispersi hasil pengukuran di lapangan melalui proses iterasi sampai diperoleh nilai RMSE (Root Mean Square Error) minimum yaitu dibawah $15 \%$.

Selanjutnya, dilakukan interpretasi data metode MASW dengan cara menganalisis seluruh profil kecepatan geser terhadap kedalaman yang dihasilkan dari tiap pasangan geophone yang berdekatan dalam pengukuran. Hasil inversi kurva dispersi seluruh pasangan geophone digunakan untuk mengestimasi kecepatan geser sebagai fungsi kedalaman dalam bentuk penampang 1D. Lalu, kedalaman yang sudah diestimasi digunakan sebagai data input untuk memplotkan struktur bawah permukaan pada model penampang 2D. Selanjutnya, dilakukan klasifikasi tanah berdasarkan SNI 1726-2012 pada tiap kedalaman nilai Vs yang didapatkan.

Pada metode CPT didapatkan grafik yang berbentuk $1 \mathrm{D}$, grafik ini diplotkan ke dalam model penampang 2D dari metode MASW dan dilakukan perbandingan antara keduanya. Dengan cara, nilai qc yang didapatkan pada tiap kedalaman pengujian CPT diklasifikasikan sesuai klasifikasi tanah pada Gambar 2 dan dilihat konsistensinya menggunakan Tabel 2 atau Tabel 3 sesuai jenis tanah yang didapatkan sebelumnya, lalu dikonversikan dengan nilai N-SPT menggunakan persamaan 1 atau persamaan 2 sesuai jenis tanah yang didapatkan sebelumnya dandikonversikan untuk mendapatkan nilai Vs 
menggunakan persamaan 3. Selanjutnya, dibandingkan langsung dengan nilai Vs yang didapatkan tiap kedalaman pengujian MASW serta dilakukan klasifikasi tanah terhadap nilai Vs CPT berdasarkan SNI 1726-2012. Lalu, dilakukan penjelasan secara kualitatif untuk mengemukakan hasil yang didapatkan dan juga ditentukan tipe pondasi apa yang sesuai dengan lokasi penelitan.

\section{Hasil dan Pembahasan}

\subsection{Hasil Pengukuran MASW}

Dari hasil pengolahan data menggunakan SeisImager mengikuti panduan manual SeisImager/SW ${ }^{\mathrm{TM}}$ didapatkan kurva dispersi dan profil 1D S-Wave Velocity yang menampilkan gambaran profil kecepatan gelombang geser (Vs) terhadap kedalaman antar lapisan dari setiap lintasan yang dilakukan pengukuran. Profil 1D pada lokasi penelitian dapat dilihat pada Gambar 5.

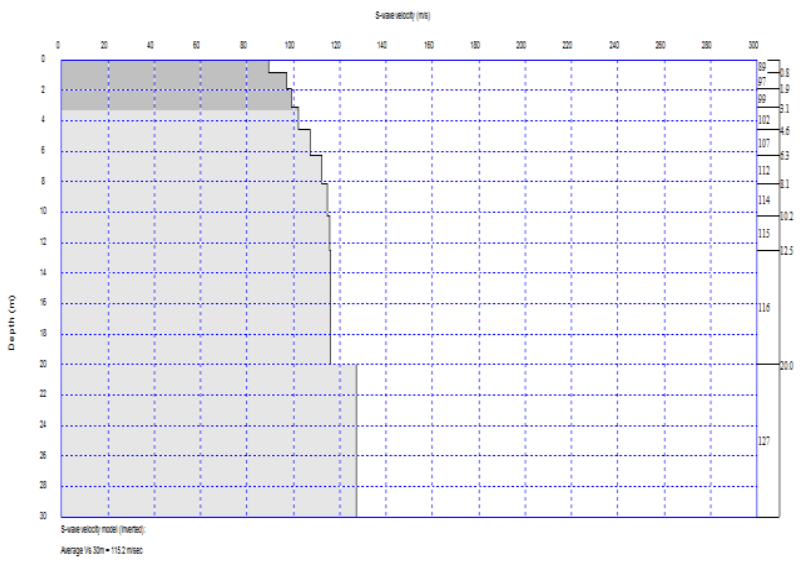

\section{Gambar 5 Profil 1D S-Wave Velocity Pada TPI Lampulo}

Proses inversi dilakukan dalam pengolahan data ini berjumlah 10 kali iterasi (pengulangan) pada setiap model 1D yang didapatkan. Proses iterasi yang dilakukan bertujuan untuk memperoleh nilai RMSE (Root Mean Square Error) minimum yaitu dibawah $15 \%$. Nilai RMSE merupakan nilai yang menunjukan presentase kesalahan dari hasil yang diperoleh. Nilai ini berasal dari pencocokan nilai untuk data yang didapatkan dari pengukuran langsung di lapangan dengan data perhitungan teoritis. Semakin kecil nilai RMSE maka semakin mendekati kondisi sebenarnya di lapangan. Nilai RMSE yang diperoleh pada lokasi penelitian adalah 2,374825\%. Hasil dari nilai RMSE menunjukkan nilai yang kecil, hal ini berarti bahwa hasil pengukuran lebih mendekati pada kondisi sebenarnya di lapangan.

\subsection{Hasil Analisis Model Penampang 2D Vs}

Hasil akhir dari pengolahan data yang dilakukan didapatkan model 2D kecepatan gelombang geser (Vs) dari hasil plot profil 1D $S$-Wave Velocity pada software Geoplot. Model 2D Vs memperlihatkan hubungan antara $S$-Wave Velocity $(\mathrm{m} / \mathrm{s})$, depth $(\mathrm{m})$, dan distance $(\mathrm{m})$ yaitu informasi berupa nilai Vs, jarak dan kedalaman serta penyebaran jenis tanah yang berada dibawah permukaan. Setiap data CPT yang didapatkan dihubungkan dengan data MASW pada jarak terdekat atau yang dilewati oleh lintasan pengukuran MASW. Berikut model 2D Vs dari hasil pengolahan data:

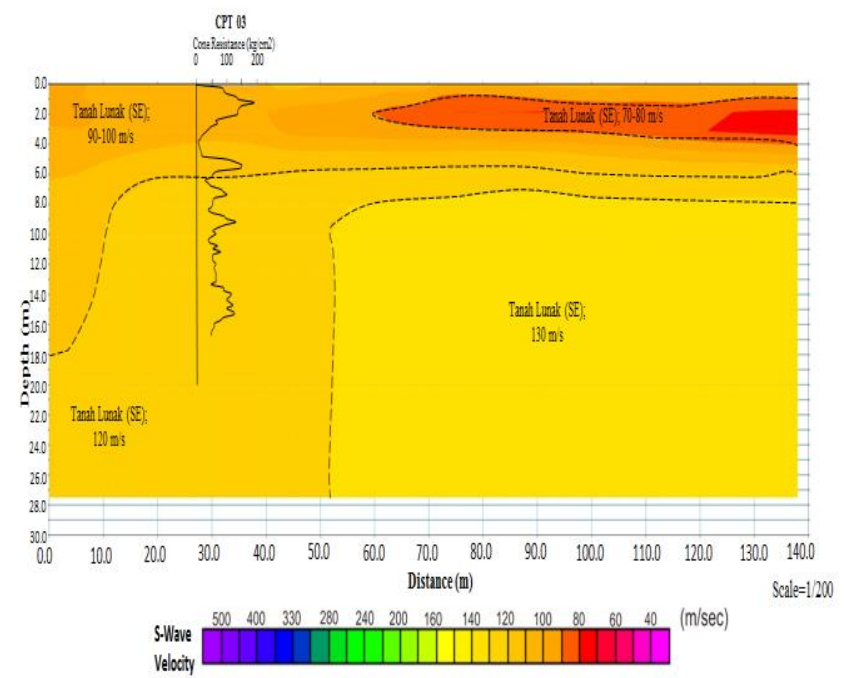

Gambar 6 Model 2D Vs TPI Lampulo

Model 2D Vs yang terlihat pada Gambar 6 menunjukkan bahwa sampai kedalaman $27,5 \mathrm{~m}$, nilai Vs memiliki rentang $70-130 \mathrm{~m} / \mathrm{s}$ yang termasuk ke dalam Tanah Lunak (SE). Berdasarkan kontur warna yang digunakan, terlihat hanya dua warna yang muncul yaitu warna merah sampai kekuningan. Setiap area yang berwarna merah memiliki nilai Vs yang rendah, yaitu 70$80 \mathrm{~m} / \mathrm{s}$ pada interval $60-138 \mathrm{~m}$ di kedalaman $0-3 \mathrm{~m}$. Begitupun dengan area yang berwarna jingga memiliki nilai Vs rendah yaitu $90-120 \mathrm{~m} / \mathrm{s}$ pada interval $0-60 \mathrm{~m}$ di kedalaman $0-27,5 \mathrm{~m}$. Area kekuningan dengan nilai Vs 130 pada interval $60-138 \mathrm{~m}$ di kedalaman $3-27,5 \mathrm{~m}$.

Pada lintasan ini tidak ada titik CPT yang melewati lintasan pengukuran MASW, maka dari itu diambil titik CPT yang berdekatan dengan lintasan pengukuran yaitu titik CPT 03 dari data CPT TPI Lampulo. Pada kedalaman $0-3,8 \mathrm{~m}$ memiliki nilai qc rata-rata sebesar $84,4 \mathrm{~kg} / \mathrm{cm} 2$ dan nilai Fr rata-rata sebesar 1,333 \% yang merupakan pasir sampai pasir berlanau dengan konsistensi medium loose (setengah lepas). Nilai qc rata-rata pada kedalaman $3,8-10,4 \mathrm{~m}$ adalah $64,205 \mathrm{~kg} / \mathrm{cm} 2$ dan nilai Fr rata-rata sebesar $1,133 \%$ yang merupakan pasir berlanau sampai lanau berpasir dengan konsistensi medium loose (setengah lepas). Selanjutnya, pada kedalaman $10,4-16,80 \mathrm{~m}$ nilai qc adalah sebesar $75 \mathrm{~kg} / \mathrm{cm} 2$ dan nilai Fr sebesar 1,1609\% 
ISSN 2685-0605

yang merupakan pasir sampai pasir berlanau dengan konsistensi medium loose (setengah lepas).

\subsection{Hasil Perbandingan Nilai Vs dan Qc Berdasarkan Persamaan Empiris}

Nilai qc yang didapatkan dari pengujian CPT dan melewati atau berdekatan dengan lintasan pengukuran MASW, dikonversikan menjadi nilai N-SPT dengan Persamaan 1 jika jenis tanah lanau atau Persamaan 2 jika jenis tanah pasir dan disubtitusikan kedalam persamaan 3 untuk dilakukan perbandingan klasifikasi tanah antara keduanya menggunakan SNI 1726-2012. Berikut hasil yang didapatkan pada lokasi penelitian:

Pada lintasan ini tidak terdapat titik CPT yang melewati lintasan pengukuran MASW, maka dari itu diambil yang paling berdekatan yaitu dengan titik CPT 03 dari CPT TPI Lampulo. Nilai qc pada CPT 03 pada setiap kedalaman dikonversikan hingga mendapatkan nilai Vs. Perbandingan nilai Vs hasil pengukuran MASW serta hasil persamaan empiris dari nilai qc pada CPT 03 terhadap klasifikasi tanah berdasarkan SNI 1726-2012 pada kedalaman tiap kelipatan $2 \mathrm{~m}$ dapat dilihat pada Tabel 4 . Grafik hubungan antara Vs MASW dan CPT dapat dilihat pada Gambar 7. Berdasarkan Tabel 4, klasifikasi tanah yang didapatkan pada nilai Vs MASW dan Vs CPT merupakan Tanah Lunak (SE).

Tabel 4 Perbandingan Hasil Nilai Vs MASW dan CPT Pada CPT 03

\begin{tabular}{ccccc}
\hline $\begin{array}{c}\text { Kedalaman } \\
(\mathrm{m})\end{array}$ & $\begin{array}{c}\text { MASW } \\
(\mathrm{m} / \mathrm{s})\end{array}$ & $\begin{array}{c}\text { Klasifikasi } \\
\text { Tanah }\end{array}$ & $\begin{array}{c}\text { Vs } \\
\text { CPT } \\
(\mathrm{m} / \mathrm{s})\end{array}$ & $\begin{array}{c}\text { Klasifikasi } \\
\text { Tanah }\end{array}$ \\
\hline 0 & 89 & $\mathrm{SE}$ & 0,00 & $\mathrm{SE}$ \\
2 & 99 & $\mathrm{SE}$ & 156,93 & $\mathrm{SE}$ \\
4 & 102 & $\mathrm{SE}$ & 32,92 & $\mathrm{SE}$ \\
6 & 107 & $\mathrm{SE}$ & 91,57 & $\mathrm{SE}$ \\
8 & 112 & $\mathrm{SE}$ & 91,57 & $\mathrm{SE}$ \\
10 & 114 & $\mathrm{SE}$ & 101,22 & $\mathrm{SE}$ \\
12 & 115 & $\mathrm{SE}$ & 101,22 & $\mathrm{SE}$ \\
14 & 116 & $\mathrm{SE}$ & 142,54 & $\mathrm{SE}$ \\
16 & 116 & $\mathrm{SE}$ & 96,47 & $\mathrm{SE}$ \\
\hline
\end{tabular}

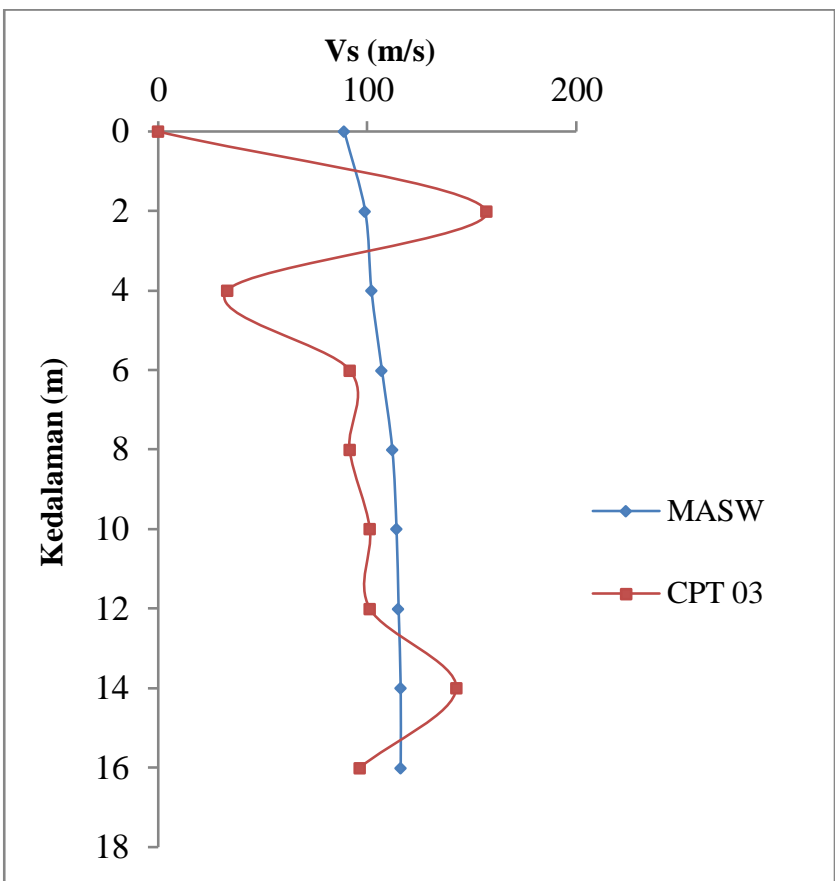

Gambar 7 Grafik Hubungan Vs MASW dan CPT Pada
TPI Lampulo

\subsection{Pembahasan}

Hasil pengujian seismik MASW pada lokasi penelitian setelah diinterpretasikan berdasarkan SNI 17262012 cenderung menghasilkan profil kekerasan tanah yang rendah karena klasifikasi tanah pada lokasi penelitian hanya memiliki satu tingkat, yaitu Tanah Lunak (SE). Hal ini selaras ketika dibandingkan dengan hasil korelasi dari nilai qc yang diperoleh dari nilai CPT. Hasil korelasi menggunakan nilai qc berdasarkan persamaan 3 menghasilkan satu variasi klasifikasi tanah yang sama, yaitu Tanah Lunak (SE).

Korelasi menggunakan persamaan empiris yang telah dikemukakan oleh para ahli memberikan hasil yang bervariasi antar satu lokasi dengan lokasi lainnya. Hal ini terjadi karena kesalahan-kesalahan yang muncul pada proses penelitian dan perbedaan kondisi geologis. Maka dari itu, diperlukan penelitian dan pengembangan lebih lanjut mengenai korelasi menggunakan persamaan empiris untuk digunakan pada lokasi yang berbeda sampai ditemukan korelasi yang lebih akurat. Korelasi yang telah ada sebaiknya hanya digunakan pada tahap investigasi awal (preliminary investigation).

Selain itu, berdasarkan sebaran rata-rata jenis tanah yang didominasi oleh tanah lunak, maka perlu diperhatikan setiap permasalahan yang berhubungan dengan stukturalnya seperti jenis pondasi. Jenis pondasi yang cocok digunakan pada lokasi penelitian adalah pondasi tiang. Hal ini didasari karena pondasi tiang dipergunakan apabila tanah keras berada pada kedalaman lebih dari 10 
meter dibawah permukaan tanah agar bangunan yang berdiri atasnya mampu berdiri secara stabil.

\section{Kesimpulan dan Saran}

\section{$5.1 \quad$ Kesimpulan}

1. Pada lokasi penelitian yang telah dilakukan pengukuran didapat nilai Vs minimum sebesar 70 $\mathrm{m} / \mathrm{s}$ dan nilai Vs maksimum sebesar $130 \mathrm{~m} / \mathrm{s}$. Berdasarkan SNI 1726-2012, tanah pada lokasi penelitian terbagi ke dalam satu kategori yaitu Tanah Lunak (SE).

2. Data CPT yang telah dikorelasikan meggunakan persamaan empiris menjadi nilai Vs menunjukkan hasil yang relatif sama dan terbagi pada satu jenis tanah yaitu Tanah Lunak (SE).

3. Dengan melihat hasil dari data CPT dan data MASW, maka jenis pondasi yang sesuai diterapkan pada lokasi penelitian adalah pondasi tiang karena letak tanah keras berada pada kedalaman lebih dari 10 meter dibawah permukaan tanah.

4. Pada penelitan yang telah dilakukan membuktikan bahwa data MASW relatif sesuai dengan data CPT unruk analisis lapisan tanah berdasarkan nilai korelasi dari persamaan-persamaan yang telah dilakukan. Maka dari itu, metode MASW bisa digunakan untuk preliminary test.

\subsection{Saran}

1. Perlu dilakukan penelitian lebih lanjut mengenai korelasi antar MASW dan CPT karena belum ditemukannya korelasi langsung ataupun persamaan empiris antar keduanya dan juga agar korelasi yang diperoleh memiliki koherensi yang baik sehingga kondisi tanah yang didapat akan lebih akurat dan detail.

2. Dikarenakan pada lokasi penelitian didominasi oleh Tanah Lunak (SE), maka diperlukan pengujian lebih lanjut untuk mendapatkan daya dukung tanah dengan menggunakan pengujian CPT.

\section{Daftar Kepustakaan}

[1] Hardiyatmo, H. C., Teknik Pondasi I Edisi Kedua, Beta Offset, 2002.

[2] Park, C. B., Miller, R. D., Xia, J., Imaging Dispersion Curves of Surface Waves on Multichannel Record, SEG Library, 1999.

[3] Yeni, L. M., Kecepatan Gelombang Geser (Vs30) untuk Pemetaan Mikrozonasi di Kecamatan Meuraxa, Banda Aceh Menggunakan Metode MASW (Multichannel Analysis of Surface Wave), Tugas Sarjana, Teknik Geofisika, FT Universitas Syiah Kuala, Banda Aceh, 2018.

[4] SNI 1726-2012, Tata Cara Perencanaan Ketahanan Gempa untuk Struktur Bangunan
Gedung dan Non Gedung, Badan Standarisasi Nasional, Jakarta, 2012.

[5] Hardiyatmo, H. C., Analisis dan Perancangan Pondasi Bagian I, Gadjah Mada University Press, Yogyakarta, 2010.

[6] Terzaghi, K., Peck, R. B., dan Mesri, G., Soil Mechanis In Engineering Practice, John Willey\&Son Inc, 1996.

[7] Marto, A., Soon, T. C., dan Kasim, F. A., Correlation of Shear Wave Velocity and Standard Penetration Resistance, The Electric Journal of Geothechinical Engineering, V(18), 464-471, 2013

[8] Rizki, M., Investigasi Geoteknik Sub Permukaan Menggunakan Metode MASW di Lokasi Pembangunan Jembatan Lamnyong Kota Banda Aceh, Tugas Sarjana, Teknik Sipil, FT Universitas Syiah Kuala, Banda Aceh, 2018.

[9] Sosrodarsono, dan Nakazawa, Mekanika Tanah dan Teknik Pondasi, PT. Pradnya Paramita, Jakarta, 1990. 